\title{
Prevalence, pattern and risk factors of retinal vein occlusion in an elderly population in Nepal: the Bhaktapur retina study
}

Raba Thapa ${ }^{1,4^{*}}$, Sanyam Bajimaya', Govinda Paudyal', Shankar Khanal' ${ }^{2}$ Stevie Tan³, Suman S. Thapa ${ }^{1}$ and Ger van Rens ${ }^{3}$

\begin{abstract}
Background: This study aims to explore the prevalence, pattern and risk factors of retinal vein occlusion (RVO) in an elderly population of Nepal.

Method: One thousand eight hundred sixty subjects of age 60 years and above were enrolled in a populationbased, cross-sectional study. Detailed history, visual acuity, anterior segment and posterior segment examinations were done. Blood pressure, non-fasting blood sugar, body mass index and abdominal girth were measured. Retinal vein occlusions were further divided into branch retinal (BRVO), hemi-retinal and central retinal vein occlusion (CRVO).

Result: Age ranged from 60 to 95 years with a mean of $69.64 \pm 7.31$ years. Overall population prevalence for RVO was 2.95\% (95\% Confidence interval (Cl): 2.23-3.83), BRVO 2.74\% (95\% Cl: $2.05-3.58$ ) and CRVO $0.21 \%$ (95\% Cl: 0.060.55). BRVO was seen in 51 subjects (92.73\%) and CRVO in 4 (7.27\%). Among the total RVO, unilateral and bilateral involvement was $85.45 \%$ and $14.55 \%$, respectively. Among the subjects with BRVO and CRVO, 37.25\% and 50\% had low vision, respectively. The risk of RVO increased with ageing and was more among males. There was an increased risk of RVO among those with hypertension, and with diabetes and hypertension. There was also an increased risk of RVO among subjects with hypermetropia, those with pseudophakia and those who were smokers and consumed alcohol.
\end{abstract}

Conclusion: Retinal vein occlusion is a common retinal vascular disorder in the elderly population of Nepal. The main risk factors for RVO were increasing age and hypertension.

Keywords: Prevalence, Risk factors, Retinal vein occlusion, Branch retinal vein occlusion, Central retinal vein occlusion, Nepal

\section{Background}

Retinal diseases are an emerging cause of visual impairment and blindness in the world where retinal vein occlusions (RVO) is the second most common retinal vascular diseases after diabetic retinopathy [1-3]. Changes in life style habits which may lead to increase

\footnotetext{
* Correspondence: rabathapa@live.com

${ }^{1}$ Tilganga Institute of Ophthalmology, Kathmandu, Nepal

${ }^{4}$ Vitreo-retina Service, Tilganga Institute of Ophthalmology, P O Box, Kathmandu 561, Nepal

Full list of author information is available at the end of the article
}

in systemic diseases such as hypertension, diabetes mellitus, cardiovascular diseases and hyperlipidaemia predispose to retinal problems [4-8]. Untimely detection and delayed treatment can result in irreversible visual impairment and blindness from vision threatening sequelae [9-12].

Several studies conducted in the Caucasian population aged from 40 years and above have shown that the prevalence of branch retinal vein occlusion (BRVO) and central retinal vein occlusion (CRVO) ranges between $0.6 \%-1.1 \%$ and $0.1-0.4 \%$, respectively [13-15]. In the 
few Asian studies, the prevalence of BRVO and CRVO was $0.6 \%$ and $0.2 \%$ in those more than 40 years of age $[16,17]$. RVO was the most common retinal vascular disease in a population based study of Nepal [18]. This is the first population-based study to estimate the pattern and risk factors for RVO in Nepal.

\section{Methods}

\section{Study population}

Bhaktapur district has 2 municipalities and 161 village development committees. According to the 2001 census the population of Bhaktapur was 298,704 and 48,223 were above the age of 40 years. In the Bhaktapur Glaucoma Study (BGS) conducted from 2007 to 2010, a WHO 30 cluster sampling method was used. From these 30 clusters, a house to house enumeration was done and a name list prepared. From this name list 4800 subjects above the age of 40 years were selected using a EPIINFO software, version 3.5.1 [19]. From these 4800 subjects only those above 60 years of age were re-invited for an examination. The total sample size of the Bhaktapur Retina Study (BRS) was 2100 of which 62\% is the surviving sample of the BGS. From the remaining subjects above the age of 60 years, $15 \%$ of the subjects had passed away, $5 \%$ had moved to other places while $18 \%$ of the subjects were unable to visit the study site. In order to meet the calculated sample size of 2100 , the rest $38 \%$ were selected from the adjoining clusters as a cross sectional survey. Two female community health workers visited the subjects at their homes and invited them to participate in the study. The required sample size for this study was estimated to be 2100 subjects after assuming 7\% prevalence for vitreo-retinal disorders in individuals 60 years and older, a relative precision of $25 \%, 85 \%$ compliance, and a design effect of 2 . The $7 \%$ prevalence of vitreo-retinal disorder was derived from the occurrence of retinal disorders in the BGS [18]; however, this analysis has been carried out with 1860 subjects $(88.57 \%)$ with complete information after excluding other subjects with incomplete information. The prevalence and risk factors of RVO were assessed in this population. All subjects were referred to the primary eye care centre of Bhaktapur district for a detailed evaluation. The study was conducted from August 2013 to December 2015.

A structured questionnaire was developed to assess the prevalence and risk factors for RVO. Mid-level ophthalmic personnel were involved in the interview, and two ophthalmologists were involved in examination of study subjects. 50 cases were pre-tested. No respondents reported difficulties in answering the questionnaire, and there were no statistically significant variations in examination findings. When the subjects were able to read and write in the national language, they were categorized as literate as defined by the Government of Nepal. The predominant profession was considered as the occupation.

\section{Patient examination and retinal vein occlusion assessment}

All patients provided a detailed ocular and medical history, followed by anterior segment and dilated fundus examinations including measurement of intraocular pressure. The best corrected visual acuity (BCVA) was assessed using the logarithm of minimum angle of resolution (log MAR) with tumbling E charts placed at $4 \mathrm{~m}$. Two retina specialists performed standardized eye examinations on the patients. A total of five fundus photographs were taken of each eye after mydriasis using a digital fundus camera (Canon) by a trained mid-level ophthalmic technician who had been government certified course to provide primary eye care in ophthalmology.

Visual impairment was based on the International Classification of Disease 10th edition [20]. Briefly, visual impairment was defined as visual acuity (VA) less than $6 / 18(<20 / 60 ;<0.3$ Log MAR) in the better eye with best correction. Low vision was defined as a BCVA of less than $6 / 18(<20 / 60 ;<0.3$ Log MAR) but not less than $3 /$ 60 (20/400; 1.3 Log MAR) in the better eye. A VA of less than $3 / 60(<20 / 200 ;<1.3 \log$ MAR) with best correction in the better eye was considered blindness.

RVO was grouped into central retinal vein occlusion, hemi-central retinal vein occlusion (Hemi-CRVO) and branch retinal vein occlusion. Briefly, in BRVO, there is occlusion of a branch of a retinal vein system and is further divided into major BRVO and macular BRVO. In CRVO, the occlusion is located in the central retinal vein and is further divided into ischemic and nonischemic types. The hemi CRVO, where there is involvement of only one half of retina surface was also divided in to ischemic and non-ischemic types [21, 22].

\section{Assessment and definitions of risk factors}

A detailed history was obtained using a standardized questionnaire. All subjects underwent blood examination for non-fasting blood sugar levels, and measurements of blood pressure, height, weight, and abdominal girth were recorded using standard techniques. Age, gender, education status, occupation, smoking, alcohol consumption, sunlight exposure, consumption of antioxidant vitamins, and presence of systemic problems like diabetes mellitus, hypertension, hyperlipidaemia, and other cardiac disorders were elicited from the self-reported history. Body mass index (BMI) was calculated by the formula; Body Mass Index = weight in kilograms divided by the square of the height in meters $\left(\mathrm{Kg} / \mathrm{m}^{2}\right)$. Venous blood samples were taken for assessment of non-fasting blood sugar. The diagnosis of diabetes mellitus was based on either the use of diabetic medications or a random blood sugar level of $200 \mathrm{mg} / \mathrm{dl}$ or greater $[18,23]$. Blood pressure 
(BP) was measured on all subjects who were categorized as hypertensive if systolic blood pressure was $140 \mathrm{mmHg}$ or more, diastolic blood pressure was $90 \mathrm{mmHg}$ or more, or if they used antihypertensive medications.

The study was approved by the Institutional Review Board and Ethics Committee of Tilganga Institute of Ophthalmology (TIO) and conducted in accordance with the Declaration of Helsinki. Informed consent was written in the vernacular and was read out for those unable to read. Subjects were asked to sign the consent form, and thumb impressions were taken for those unable to sign prior to enrollment in the study.

\section{Statistical analysis}

Summary measures such as mean \pm sd for continuous variables and percentages for categorical variables were computed. Comparisons of continuous variables between two groups were analyzed by using independent t- tests, and the associations between two categorical variables were assessed using Chi-square or Fisher's exact test wherever applicable. Presence of retinal vein occlusion was considered as a binary outcome variable. In order to quantify the effect of different risk factors on the outcome variable, they were measured thorough the use of logistic regression. The prevalence of CRVO, BRVO, etc. was computed with $95 \%$ confidence intervals. Results were considered significant at $5 \%$ level of significance ( $p$ value $\leq 0.05$ ). All of the statistical analyses were performed using STATA 9.0.

\section{Results}

Complete information was available for 1860 subjects (88.57\%). The non-responder and responder groups were compared with regard to age and gender. There was no significant difference observed between age and gender among the two groups (Table 1).

The characteristics of the study population in various stages of RVO are shown in Table 2. The age ranged from 60 to 95 years with a mean age of $69.64 \pm 7.31$ years. Half of the subjects (51.08\%) were between 60 and 69 years of age, whereas $11.45 \%$ were 80 years and above. More females 1039 (55.86\%) participated in the study. Among the total, $1433(77.04 \%)$ were illiterates, and $1351(72.63 \%)$ were farmers by occupation.

RVO was found in 55 subjects in the study population with an overall population prevalence of $2.95 \%$ (95\%

Table 1 Comparison of responders and non responders in the study population

\begin{tabular}{llll}
\hline Variable & $\begin{array}{l}\text { Responders } \\
(n=1860)\end{array}$ & $\begin{array}{l}\text { Non responders } \\
(n=240)\end{array}$ & $p$-value \\
\hline Mean age (Years) & $69.64 \pm 7.31$ & $69.50 \pm 7.93$ & 0.782 \\
Male, $\mathrm{n}(\%)$ & $821(44.14)$ & $110(45.83)$ & 0.629 \\
Female, $\mathrm{n}(\%)$ & $1039(55.86)$ & $130(54.17)$ & \\
\hline
\end{tabular}

Confidence interval (CI); 2.23-3.83). BRVO was found in 51 subjects $(92.73 \%)$ and CRVO in 4 subjects $(7.27 \%)$ among the RVO subjects. The population prevalence of BRVO was $2.74 \%$ (95\% CI: $2.05-3.58$ ) and CRVO 0.21\% (95\% CI: 0.06-0.55). Among the total number of RVO subjects, unilateral involvement was documented in 47 subjects $(85.45 \%)$, while involvement was bilateral in 8 subjects (14.55\%).

Table 2 shows the demographic characteristics of the persons with RVO. Almost half (49.09\%) of the total number of subjects with RVO was within the age range of 60-69 years. Similarly, among the total BRVO and CRVO subjects, both BRVO (47.06\%) and CRVO (75\%) were higher in the age group 60-69 years.

RVO, BRVO and CRVO each was seen more common among females, agricultural occupation, and illiterates. However, this was not statistically significant amongst the groups.

Among the study subjects, hypertension was found in $45.45 \%$ in RVO, $56.07 \%$ in BRVO and $25 \%$ in CRVO. Only $7.27 \%$ of subjects with RVO had diabetes mellitus, and all of them had BRVO. RVO was found in $5.45 \%$ of the subjects having both diabetes and hypertension, and all CRVO patients had both diabetes and hypertension. RVO was also higher $(60.78 \%)$ among the subjects with BMI less than $24.9 \mathrm{Kg} / \mathrm{m}^{2}$. The mean abdominal girth was higher among the subjects with BRVO (78.53\%) than in CRVO (76.50\%). 63.64\% of RVO subjects had BCVA less than 0.3 Log MAR. Myopia and hypermetropia was found in $10.91 \%$ and $3.45 \%$ of RVOs respectively, while the rest of the subjects had mixed types of refractive error and astigmatism. None of the subjects with CRVO had hypermetropia. Pseudophakia was found in $21.82 \%$ of RVO subjects, and $50 \%$ of the subjects with CRVO had pseudophakia. $60 \%$ of those with RVO were smokers, $60.78 \%$ of subjects with BRVO, and $50 \%$ of the subjects with CRVO were smokers. $41.82 \%$ of the subjects with RVO were alcohol consumers (Table 3).

$38.18 \%$ of RVO subjects had low vision in better eyes in best correction. Among the subjects with BRVO and CRVO, low vision was found in $37.25 \%$ and $50 \%$, respectively, but the difference was not statistically significant $(p=0.613)$ (Table 4).

There was a slight increase in the risk of developing RVO in the 70-79 year age group when compared to other age groups; however, this was not statistically significant. Males, agricultural occupation, and illiterates also had a higher risk of RVO but this was not statistically significant.

There was increased risk of RVO among those with hypertension, and those having both diabetes and hypertension. The risk was lower, however, among the subjects who had only diabetes. High body mass index and abdominal girth were not associated with RVO. 
Table 2 Demographic characteristics among subjects with retinal vein occlusion

\begin{tabular}{|c|c|c|c|c|c|}
\hline Demographic characteristics & $\begin{array}{l}\text { All Persons (N/\%) } \\
(N=1860)\end{array}$ & $\begin{array}{l}\text { RVO Total } \\
(\mathrm{N} / \%)(N=55)\end{array}$ & $\begin{array}{l}\text { BRVO } \\
(\mathrm{N} / \%)(N=51)\end{array}$ & $\begin{array}{l}\text { CRVO (N/\%) } \\
(N=4)\end{array}$ & $p$-value \\
\hline \multicolumn{6}{|l|}{ Age(years) } \\
\hline $60-69$ & $950(51.08)$ & $27(49.09)$ & $24(47.06)$ & $3(75)$ & \multirow[t]{3}{*}{0.521} \\
\hline 70-79 & $697(37.47)$ & $22(40)$ & $21(41.18)$ & $1(25)$ & \\
\hline$\geq 80$ & $213(11.45)$ & $6(10.91)$ & $6(11.76)$ & 0 & \\
\hline \multicolumn{6}{|l|}{ Gender } \\
\hline Male & $821(44.14)$ & $25(45.45)$ & $24(47.06)$ & $1(25)$ & \multirow[t]{2}{*}{0.394} \\
\hline Female & $1039(55.86)$ & $30(54.55)$ & $27(52.94)$ & $3(75)$ & \\
\hline \multicolumn{6}{|l|}{ Occupation } \\
\hline Agriculture & $1351(72.63)$ & $40(72.73)$ & $37(72.55)$ & $3(75)$ & \multirow[t]{2}{*}{0.916} \\
\hline Other occupations & $509(27.37)$ & $15(27.27)$ & $14(27.45)$ & $1(25)$ & \\
\hline \multicolumn{6}{|l|}{ Education status } \\
\hline Illiterates & $1433(77.04)$ & $48(87.27)$ & $44(86.27)$ & $4(100)$ & \multirow[t]{2}{*}{0.428} \\
\hline Literates & $427(22.96)$ & $7(12.73)$ & $7(13.73)$ & 0 & \\
\hline
\end{tabular}

RVO Retinal vein occlusion, BRVO Branch retinal vein occlusion, CRVO Central retinal vein occlusion

Similarly, there was an increased risk of RVO among the subjects with hypermetropia and pseudophakia, although this was not statistically significant. The risk of RVO was also high among those who consumed alcohol and tobacco. No variable was a significant risk factor for retinal vein occlusion when we performed univariate logistic regression analysis (Table 5).

\section{Discussion}

This is the first population-based study to estimate the pattern and risk factors of retinal vein occlusion in Nepal. The outcomes of the study can help apply measures in the community to reduce blinding sequelae of RVO.

The overall population prevalence of RVO in this study was $2.95 \%$. This was slightly higher than other population based studies conducted in the developed and developing countries that ranged from 0.6 to $1.6 \%$ $[13,15,16,24,25]$. One possible reason for the higher prevalence could be due to the more elderly age of our participants. Our study may be compared with a another conducted by Mitchell et al. in Australia [12] where the prevalence of RVO was $1.2 \%$ for the age group 60 69 years, $2.1 \%$ for the age group $70-79$ years and $4.6 \%$ for the age group 80 years or older. In our study, the prevalence of RVO was $2.84 \%$ for the age group 60 69 years, $3.15 \%$ for the age group $70-79$ years, and $2.82 \%$ for the age group 80 years and above. The prevalence of RVO was slightly higher in the younger age group in this study as compared to the Mitchell et al. however; the prevalence of RVO at the age group 80 years and above was lower in our study. In our study, the mean age of the study participants was $69.64 \pm 7.31$ years and study was conducted at the age
60 years and above. The study participants included 49 years and above in the series of Mitchell et al. The possible reason could be due to the variation in sample size between the two studies (3654 in Mitchell et al. whereas 1860 in this study).

The population prevalence of BRVO was 2.74\%, which was slightly higher than studies conducted in the Caucasian and Asian races which ranged from 0.6-1.1\% [14-17]. This difference again could be attributed to the more elderly people in our study. BRVO was more common than CRVO in this study, comprising $92.73 \%$ of total RVO, 12.75 times more frequent than CRVO, which is similar to other studies $[1,6,7,12]$. BRVO is commonly associated with systemic hypertension $[8,25,26]$. Systemic hypertension occurs more frequently in the elderly population [27] which could be the reason for a higher prevalence of BRVO in our elderly population [8]. Since our sample did not estimate CRVO in a younger age group ( $<60$ years) where it is seen more frequently $[11,29]$. We could have also underestimated the prevalence of CRVO. The population prevalence of CRVO was $0.21 \%$. The finding was consistent with other studies where prevalence ranged from $0.1-0.4 \%[13,16,17]$.

There was bilateral involvement in $14.55 \%$ with RVO in our study. Mitchell et al. [12] reported bilateral involvement in $5.1 \%$ of subjects. The higher percentage in our population could be due to more elderly population and also uncontrolled systemic diseases. The glycosylated hemoglobin and lipid panel would be helpful for further analysis. The difference in the laterality may be due to variation in sample size between the two study.

Bilateral involvement is a serious public health issue which can lead to visual impairment. 
Table 3 Systemic, ocular conditions and social habits among the subjects with retinal vein occlusion

\begin{tabular}{|c|c|c|c|c|}
\hline Systemic Conditions & RVO Total (N, \%) & $\begin{array}{l}\text { BRVO } \\
(\mathrm{N}, \%)\end{array}$ & $\begin{array}{l}\text { CRVO } \\
(\mathrm{N}, \%)\end{array}$ & $p$-value \\
\hline \multicolumn{5}{|l|}{ Hypertension } \\
\hline No Hypertension & $30(54.55)$ & $27(52.94)$ & $3(75)$ & \multirow[t]{2}{*}{0.394} \\
\hline Hypertension & $25(45.45)$ & $24(47.06)$ & $1(25)$ & \\
\hline \multicolumn{5}{|l|}{ Diabetes Mellitus } \\
\hline No diabetes mellitus & $51(92.73)$ & $47(92.16)$ & $4(100)$ & \multirow[t]{2}{*}{0.561} \\
\hline Diabetes mellitus & $4(7.27)$ & $4(7.84)$ & 0 & \\
\hline \multicolumn{5}{|c|}{ Combined diabetes and hypertension } \\
\hline No diabetes and hypertension & $52(94.55)$ & $48(94.11)$ & $4(100)$ & \multirow[t]{2}{*}{0.618} \\
\hline Diabetes and hypertension & $3(5.45)$ & $3(5.89)$ & 0 & \\
\hline \multicolumn{5}{|l|}{$\mathrm{BMI}\left(\mathrm{Kg} / \mathrm{m}^{2}\right)$} \\
\hline$\leq 24.9$ & $34(61.82)$ & $31(60.78)$ & $3(75)$ & \multirow[t]{2}{*}{0.573} \\
\hline$\geq 25$ & $21(38.18)$ & $20(39.22)$ & $1(25)$ & \\
\hline Abdominal girth (mean in cm) & $78.38 \pm 11.09$ & $78.53 \pm 9.49$ & $76.5 \pm 10.75$ & 0.408 \\
\hline \multicolumn{5}{|l|}{ Ocular Factors } \\
\hline \multicolumn{5}{|l|}{ BCVA(Log MAR) } \\
\hline$<0.3$ & $35(63.64)$ & $33(64.71)$ & $2(50)$ & \multirow[t]{2}{*}{0.556} \\
\hline$>0.3$ & $20(36.36)$ & $18(35.29)$ & $2(50)$ & \\
\hline \multicolumn{5}{|l|}{ Refractive error } \\
\hline Myopia & $6(10.91)$ & $5(9.80)$ & $1(25)$ & \multirow[t]{3}{*}{0.589} \\
\hline Hypermetropia & $3(5.45)$ & $3(5.88)$ & 0 & \\
\hline Astigmatism & 46 (83.64) & $43(84.31)$ & $3(75)$ & \\
\hline \multicolumn{5}{|l|}{ Lenticular status } \\
\hline No pseudophakia & $43(78.18)$ & $41(80.39)$ & $2(50)$ & \multirow[t]{2}{*}{0.156} \\
\hline Pseudophakia & $12(21.82)$ & $10(19.61)$ & $2(50)$ & \\
\hline \multicolumn{5}{|l|}{ Social habits } \\
\hline \multicolumn{5}{|l|}{ Smoking } \\
\hline Never & $22(40)$ & $20(39.22)$ & $2(50)$ & \multirow[t]{3}{*}{0.913} \\
\hline Present & $17(30.91)$ & $16(31.37)$ & $1(25)$ & \\
\hline Past & $16(29.09)$ & $15(29.41)$ & $1(25)$ & \\
\hline \multicolumn{5}{|l|}{ Alcohol consumption } \\
\hline Never & $22(40)$ & $20(39.22)$ & $2(50)$ & \multirow[t]{3}{*}{0.775} \\
\hline Present & $23(41.82)$ & $22(43.14)$ & $1(25)$ & \\
\hline Past & 10 (18.18) & $9(17.65)$ & $1(25)$ & \\
\hline
\end{tabular}

RVO Retinal vein occlusion, BRVO Branch retinal vein occlusion, CRVO Central retinal vein occlusion, BCVA Best corrected visual acuity

Table 4 Best Corrected Visual acuity among the subjects with RVO

\begin{tabular}{llll}
\hline Visual Acuity & Total RVO & $\begin{array}{l}\text { BRVO } \\
(\mathrm{N}, \%)\end{array}$ & $\begin{array}{l}\text { CRVO } \\
(\mathrm{N}, \%)\end{array}$ \\
\hline Normal visual acuity & $34(61.82)$ & $32(62.75)$ & $2(50)$ \\
Low vision & $21(38.18)$ & $19(37.25)$ & $2(50)$ \\
Total & $55(100)$ & $52(100)$ & $4(100)$ \\
\hline
\end{tabular}

RVO Retinal vein occlusion, BRVO Branch retinal vein occlusion, CRVO Central retinal vein occlusion
BRVO and CRVO rates were high among subjects with hypertension, which is consistent with other studies [6-8, 12, 24, 26, 28]. Among the subjects with RVO, four were diagnosed with diabetes mellitus and all were BRVO, which implies that DM could be a risk factor for BRVO. Diabetes mellitus has been found to be a risk factor for CRVO [8, 24, 26]. However, due the low number of subjects with CRVO in our study, we are unable to comment further on diabetes as a risk factor in this population. 
Table 5 Risk factors for retinal vein occlusion using logistic regression analysis

\begin{tabular}{|c|c|c|c|c|}
\hline Characters & $\begin{array}{l}\text { No RVO } \\
(n=1805) \\
\text { Number (\%) }\end{array}$ & $\begin{array}{l}\text { RVO } \\
(n=55) \\
\text { Number (\%) }\end{array}$ & $\begin{array}{l}\text { Odds Ratio } \\
\text { (95\% Confidence Interval) }\end{array}$ & $P$ - value \\
\hline \multicolumn{5}{|l|}{ Age in Years, n (\%): } \\
\hline $60-69$ & $923(51.14)$ & $27(49.09)$ & 1.00 & \\
\hline $70-79$ & $675(37.40)$ & $22(40.00)$ & $1.11(0.62-1.97)$ & 0.711 \\
\hline$\geq 80$ & $207(11.47)$ & $6(10.91)$ & $0.99(0.40-2.43)$ & 0.984 \\
\hline \multicolumn{5}{|l|}{ Gender: } \\
\hline Male, n(\%) & $796(44.10)$ & $25(45.45)$ & 1.00 & \\
\hline Female, n(\%) & $1009(55.90)$ & $30(54.55)$ & $0.94(0.55-1.62)$ & 0.842 \\
\hline \multicolumn{5}{|l|}{ Occupation: } \\
\hline Agriculture & $1311(72.63)$ & $40(72.73)$ & 1.00 & 0.987 \\
\hline other occupations & $494(27.37)$ & $15(27.17)$ & $0.99(0.54-1.82)$ & \\
\hline \multicolumn{5}{|l|}{ Literacy: } \\
\hline Illiterate & $1385(76.73)$ & $48(87.27)$ & 1.00 & \\
\hline Literates & $420(23.27)$ & $7(12.73)$ & $0.48(0.21-1.07)$ & 0.073 \\
\hline \multicolumn{5}{|l|}{ All Hypertension } \\
\hline No & $1187(65.16)$ & $30(54.55)$ & 1.00 & \\
\hline Yes & $618(34.24)$ & $25(45.45)$ & $1.60(0.93-2.74)$ & 0.088 \\
\hline \multicolumn{5}{|l|}{ Known Hypertensive } \\
\hline No & $1401(72.62)$ & $36(65.45)$ & 1 & \\
\hline Yes & $404(22.38)$ & $19(34.55)$ & $1.83(1.03-3.22)$ & 0.037 \\
\hline \multicolumn{5}{|l|}{ Newly diagnosed Hypertensive } \\
\hline No & $1587(87.92)$ & $49(89.09)$ & 1 & \\
\hline Yes & $218(12.08)$ & $6(10.91)$ & $0.89(0.37-2.10)$ & 0.793 \\
\hline \multicolumn{5}{|l|}{ Diabetes } \\
\hline No & $1641(90.91)$ & $51(92.73)$ & 1.00 & \\
\hline Yes & $164(9.09)$ & $4(7.27)$ & $0.78(0.28-2.18)$ & 0.645 \\
\hline \multicolumn{5}{|l|}{ Known diabetes } \\
\hline No & $1672(92.63)$ & $51(92.73)$ & 1 & \\
\hline Yes & $133(7.37)$ & $4(7.27)$ & $0.98(0.35-2.76)$ & 0.979 \\
\hline \multirow[t]{2}{*}{ Newly diagnosed diabetes } & $1774(98.28)$ & $55(100)$ & & \\
\hline & $31(1.72)$ & 0 & & 0.327 \\
\hline \multicolumn{5}{|c|}{ Combined HTN and Diabetes mellitus } \\
\hline No & $1710(94.74)$ & $52(94.55)$ & 1.00 & \\
\hline Yes & $95(5.26)$ & $3(5.45)$ & $1.03(0.31-3.38)$ & 0.950 \\
\hline \multicolumn{5}{|l|}{ Body Mass Index $\left(\mathrm{kg} / \mathrm{m}^{2}\right)$} \\
\hline$(<24.9)$ & $1103(61.11)$ & $34(61.82)$ & 1.00 & \\
\hline$(>25)$ & $702(38.89)$ & $21(38.18)$ & $0.97(0.55-1.68)$ & 0.915 \\
\hline $\begin{array}{l}\text { Body Mass Index }\left(\mathrm{kg} / \mathrm{m}^{2}\right) \\
(\text { mean } \pm \text { S.D) }\end{array}$ & $23.66 \pm 4.00$ & $23.41 \pm 4.58$ & $0.98(0.92-1.05)$ & 0.654 \\
\hline Abdominal girth (mean \pm S.D) & $80.29 \pm 11.13$ & $78.38 \pm 9.49$ & $0.98(0.95-1.00)$ & 0.203 \\
\hline \multicolumn{5}{|l|}{ BCVA (Log MAR) } \\
\hline$<0.3$ & $1139(63.10)$ & $35(63.64)$ & 1.00 & 0.936 \\
\hline$>0.3$ & $666(36.90)$ & $20(36.36)$ & $0.97(0.55-1.70)$ & \\
\hline
\end{tabular}


Table 5 Risk factors for retinal vein occlusion using logistic regression analysis (Continued)

\begin{tabular}{|c|c|c|c|c|}
\hline Myopia & $181(10.03)$ & $6(10.91)$ & 1.00 & \\
\hline Hypermetropia & $246(13.63)$ & $3(5.45)$ & $1.17(0.75-1.85)$ & 0.215 \\
\hline Others & $1378(76.34)$ & $46(83.64)$ & $1.00(0.42-2.39)$ & 0.987 \\
\hline \multicolumn{5}{|l|}{ Pseudophakia } \\
\hline No & $1526(85.10)$ & $43(78.18)$ & 1.00 & \multirow[t]{2}{*}{0.162} \\
\hline Yes & 269 (14.90) & $12(21.82)$ & $1.59(0.82-3.06)$ & \\
\hline \multicolumn{5}{|l|}{ Smoking } \\
\hline Non smoker & 790 (43.74) & $22(40)$ & 1.00 & \multirow[t]{2}{*}{0.582} \\
\hline Smoker & $1016(56.26)$ & $33(60)$ & $1.16(0.67-2.01)$ & \\
\hline \multicolumn{5}{|l|}{ Alcohol } \\
\hline No Alcohol & $772(42.20)$ & $22(40)$ & 1.00 & \multirow[t]{2}{*}{0.685} \\
\hline Alcohol & $1034(57.25)$ & $33(60)$ & $1.11(0.64-1.93)$ & \\
\hline
\end{tabular}

RVO Retinal vein occlusion, HTN Hypertension, BCVA Best corrected visual acuity

There are several studies, which have found hypermetropia as a risk factor for CRVO [6, 29]. However, in our study none of the subjects with CRVO had hypermetropia, and thus we are unable to comment on the role of hypermetropia as a risk factor for CRVO, but hypermetropia was seen more frequently in those with BRVO, which is similar to other studies [30]. Almost one third subjects with BRVO and half of the subjects with CRVO had poor visual acuity. Our finding was similar to the series by Mitchell et al. [12].

The risk of RVO was higher with increasing age [12, 24]. RVO was more commonly seen in males, but gender did not prove to be a significant risk factor $[1,25,26]$. We are unable to correlate occupation and literacy as risk factors for RVO because the large majority of the sample population belonged to an agricultural occupation and were illiterate.

The risk of RVO was higher among those with hypertension in this study. This finding was consistent with other hospital-based and population-based studies across the globe $[6,7,12,15,26,28]$. Similarly, combined diabetes and hypertension was associated with an increase in risk of developing $\operatorname{RVO}[6,7,26]$. The risk of RVO was low among subjects with diabetes unlike other studies where diabetes was a risk factor of $\operatorname{RVO}[7,8,26]$. The risk of RVO was high among those with hypermetropia as compared to myopia in this study. This finding was consistent with other hospital-based and population-based studies from both the developed and developing world $[6,30]$. The higher risk of RVO among the subjects with pseudophakia in this study may be associated with an increase in age.

The risk of RVO was higher among the subjects who consumed alcohol and those who were smokers, similar to the series by Klein et al. [13]. The prevalence of RVO diseases is mostly related to systemic diseases such as HTN and DM. The prevalence of RVO can decrease by reducing the rates of DM and HTN and keeping them under control. Screening of high-risk subjects for early detection and timely treatment will reduce the blinding sequelae from RVO [2, 4-32].

The strength of the study is the large sample size of the elderly age group. The major limitation of the study is that we are not able to comment on the prevalence and risk factors of RVO in the younger segment of the study population. Other limitations are that glycosylated haemoglobin and lipid panel tests were not possible to conduct in this population based study for further exploration of risk factors.

\section{Conclusion}

Retinal vein occlusion is a common retinal vascular disorder in the elderly population of Nepal. The main risk factors of RVO were increasing age and hypertension. Regular eye examinations in the high-risk group coupled with timely detection and treatment of retinal vascular occlusions could help prevent blindness in this elderly age population.

\section{Abbreviations}

BCVA: Best corrected visual acuity; BGS: Bhaktapur Glaucoma Study; BMI: Body mass index; BP: Blood pressure; Cl: Confidence interval; CRVO: Central retinal vein occlusion; DM: Diabetes mellitus; Hemi CRVO: hemi central retinal vein occlusion; HTN: Hypertension; LogMAR: Logathirm of Minimum Angle of Resolution; N: Number; N: Number; RVO: Retinal vein occlusion; S.D.: Standard deviation; TIO: Tilganga Institute of Ophthalmology

\section{Acknowledgments}

We would like to acknowledge Tilganga Institute of Ophthalmology, Kathmandu, Nepal, Vrije University Medical Center, Amsterdam, The Netherlands, all the patients who participated in this study and the Bhaktapur Municipality for all the supports. Professor Paul S. Bernstein MD, $\mathrm{PhD}$ of the Moran Eye Center of the University of Utah, USA edited the manuscript.

\section{Funding}

This study is funded by Vrije University Medical Center, Amsterdam, The Netherlands and Tilganga Institute of Ophthalmology, Kathmandu, Nepal. 


\section{Availability of data and materials}

All data generated or analyzed during this study are included in this published article.

\section{Authors' contributions}

RT carried out the Bhaktapur Retina Study, participated in coordination, study concept, study design, data collection, data analysis, and prepared the manuscript. SB participated in data collection. GP was involved in critical analysis of the manuscript. SK participated in study design and performed statistical analysis and critical review of the manuscript. SHT was involved in study design and critical analysis of the manuscript. SST participated in coordination, study design, manuscript preparation, and critical analysis. GVR was involved in study concept, study design, and critical analysis of the manuscript. All authors read and approved the final manuscript.

\section{Ethics approval and consent to participate}

The study was approved by the Institutional Review Board and Ethics Committee of Tilganga Institute of Ophthalmology and conducted in accordance with the Declaration of Helsinki. Informed consent was taken from the participants before enrollment in the study.

\section{Consent for publication}

Not applicable.

\section{Competing interests}

The authors declare that they have no competing interests.

\section{Publisher's Note}

Springer Nature remains neutral with regard to jurisdictional claims in published maps and institutional affiliations.

\section{Author details}

${ }^{1}$ Tilganga Institute of Ophthalmology, Kathmandu, Nepal. ${ }^{2}$ Central Department of Statistics, Tribhuvan University, Kirtipur, Nepal. ${ }^{3}$ Vrije University Medical Center, Amsterdam, The Netherlands. ${ }^{4}$ Vitreo-retina Service, Tilganga Institute of Ophthalmology, P O Box, Kathmandu 561, Nepal.

Received: 8 August 2016 Accepted: 16 August 2017

\section{Published online: 02 September 2017}

\section{References}

1. Rogers S, Mclntosh RL, Cheung N, Lim L, Wang JJ, Mitchell P, et al. The prevalence of retinal vein occlusion: pooled data from population studies from the United States, Europe, Asia, and Australia. Ophthalmology. 2010; 117:313-91.

2. The Central Vein Occlusion Study Group. Natural history and clinical management of central retinal vein occlusion. Arch Ophthalmol. 1997;115: 486-91

3. Orth DH, Patz A. Retinal branch vein occlusion. Surv Ophthalmol. 1978;22(6): $357-76$

4. The Eye Disease Case Control Study Group. Risk factors for branch retinal vein occlusion. Am J Ophthalmol. 1993;116(3):286-96.

5. The Eye Disease Case Control Study Group. Risk factors for central retinal vein occlusion. Arch Ophthalmol. 1996;114(5):545-54

6. Thapa R, Paudyal G, Bernstein PS. Demographic characteristics, patterns, and risk factors for retinal vein occlusion in Nepal: a hospital - based case control study. Clin Exp Ophthalmol. 2010;38(6):583-90.

7. Shrestha RK, Shrestha JK, Koirala S, Shah DN. Association of systemic diseases with retinal vein occlusive disease. J Nepal Med Assoc. 2006; 45(162):244-8.

8. Lee JY, Yoon YH, Kim HK, Yoon HS, Kang SW, Kim JG, Park KH, Jo YJ, the Korea RVO study. Baseline characteristics and risk factors of retinal vein occlusion: a study by the Korean RVO study group. J Korean Med Sci. 2013; 28:136-44.

9. Hayreh SS, Podhajsky P, Zimmerman B. Natural history of visual outcome in central retinal vein occlusion. Ophthalmology. 2011;118(1):119-31.

10. Hayreh SS, Rojas P, Podhajsky P, Montague P, Woolson RE. Ocular neovascularization with retinal vascular occlusion-III. Incidence of ocular neovascularization with retinal vein occlusion. Ophthalmology. 1983:90(5): 488-506.
11. Fong AC, Schatz H. Central retinal vein occlusion in young adults. Surv Ophthalmol. 1993:37(6):393-417.

12. Mitchell $P$, Wayne $S$, Chang A. Prevalence and associations of retinal vein occlusion in Australia. The Blue Mountains eye study. Arch Ophthalmol. 1996;114(10):1243-7.

13. Klein R, Klein BE, Moss SE, Meuer SM. The epidemiology of retinal vein occlusion: the Beaver Dam Eye Study. Trans Am Ophthalmol Soc. 2000;98: $133-41$.

14. Cheung N, Klein R, wang JJ, et al. Traditional and novel cardiovascular risk factors for retinal vein occlusion: the multiethnic study of atherosclerosis. Invest Ophthalmol Vis Sci. 2008;49(10):4297-302.

15. Cugati S, Wang JJ, Kundtson MD, et al. Retinal vein occlusion and vascular mortality: pooled data analysis of 2 population based cohorts. Ophthalmology. 2007;114(3):520-4.

16. Lim LL, Cheung N, Wang JJ, et al. Prevalence and risk factors of retinal vein occlusion in an Asian population. Br J Ophthalmol. 2008;92(10):1316-9.

17. Xu L, Liu WW, Wang YX, et al. Retinal vein occlusions and mortality: the Beijing Eye Study. Am J Ophthalmol. 2007;144(6):972-3.

18. Thapa SS, Thapa R, Paudyal I, Khanal S, Aujla J, Paudyal G, Rens G. Prevalence and pattern of Vitreo-retinal disorders in Nepal: the Bhaktapur Glaucoma Study. BMC Ophthalmology. 2013;13:9. doi:10.1186/1471-2415-13-9.

19. Thapa SS, Rana PP, Twyana SN, Shrestha MK, Paudel I, Paudyal G, Gurung R, Ruit S, Hewitt AW, Craiq JE, Van Rens G. Rational, methods and baseline demographics of the Bhaktapur Glaucoma Study. Clin Experiment Ophthalmol. 2011;39:126-34.

20. World Health Organization. International Statistical Classification of Diseases and Related Health Problems. 10 ${ }^{\text {th }}$ revision edition. Geneva: WHO; 1992.

21. Hayreh SS, Zimmerman MB, Podhajsky P. Incidence of various types of retinal vein occlusion and their recurrence and demographic characteristics. Am J Ophthalmol. 1994:117(4):429-41.

22. Hayreh SS, Zimmerman MB. Branch retinal vein occlusion: natural history of visual outcome. JAMA Ophthalmology. 2014;132(1):13-22.

23. Report of World Health Organization/International Diabetes Federation consultation. Definition and diagnosis of diabetes mellitus and intermediate hyperglycaemia. World Health Organization; 2006. p. 1-50.

24. Klein R, Moss SE, Meuer SM, Klein BE. The 15-year cumulative incidence of retinal vein occlusion: the Beaver Dam Eye Study. Arch Ophthalmol. 2008; 126(4):513-8.

25. Ponto KA, Elbaz H, Peto T, Laubert-Reh D, Binder H, Wild PS, Lackner K, Pfeiffer N, Mirshahi A. Prevalence and risk factors of retinal vein occlusion: the Gutenberg Health Study. J Thromb Haemost. 2015;13(7):1254-63.

26. Hayreh SS, Zimmerman B, McCarthy M. Podhajsky P. Systemic diseases associated with various types of retinal vein occlusion. Am J Ophthalmol 2001;131(1)61-77.

27. Kshirsagar AV, Chiu Y, Bomback AS, August PA, Viera AJ, Colindres RE, Bang H. A hypertension risk score for middle-aged and older adults. J Clin Hypertens (Greenwich). 2010;12(10):800-8.

28. Malayan AS, Shakhsuvaryan ML, Grigoryan GL, Melkonyan AK. Retinal vein occlusion in Armenia. Eur J Ophthalmol. 1999;9(3):196-201.

29. Koizumi H, Ferrara DC, Brue C, Spaide RF. Central retinal vein occlusion casecontrol study. Amer J Ophthalmol. 2007;144:858-63.

30. Maijji $A B$, Janarthanan $M$, Naduvilath TJ. Significance of refractive status in branch retinal vein occlusion. A case control study. Retina. 1997;17:200-4.

31. Thapa R, Maharjan N, Paudyal G. Intravitreal bevacizumab in macular edema secondary to branch retinal vein occlusion: 12 month results. Clin Ophthalmol. 2012;11:1057-62.

32. The Central Vein Occlusion Study Group. Evaluation of grid pattern photocoagulation for macular edema in central vein occlusion. Ophthalmology. 1995;102:1425-33. 